\title{
Development of a Portable Electronic Nose for Detection of Cotton Damaged by Nezara viridula (Hemiptera: Pentatomidae)
}

\author{
Brittany D. Lampson, ${ }^{1}$ Ahmad Khalilian, ${ }^{2}$ Jeremy K. Greene, ${ }^{2}$ \\ Young J. Han, ${ }^{1}$ and David C. Degenhardt ${ }^{3}$ \\ ${ }^{1}$ School of Agricultural, Forest, and Environmental Sciences, Clemson University, 231 McAdams Hall, Clemson SC 29634, USA \\ ${ }^{2}$ School of Agricultural, Forest, and Environmental Sciences, Edisto Research and Education Center, 64 Research Road, \\ Blackville, SC 29817, USA \\ ${ }^{3}$ Richland County School System, 4801 Hardscrabble Road, Columbia, SC 29229, USA
}

Correspondence should be addressed to Ahmad Khalilian; akhlln@clemson.edu

Received 31 July 2014; Revised 20 October 2014; Accepted 21 October 2014; Published 11 November 2014

Academic Editor: José A. Martinez-Ibarra

Copyright @ 2014 Brittany D. Lampson et al. This is an open access article distributed under the Creative Commons Attribution License, which permits unrestricted use, distribution, and reproduction in any medium, provided the original work is properly cited.

Stink bugs are significant pests of cotton in the southeastern USA, causing millions of dollars in control costs and crop losses each year. New methods to detect stink bug damage must be investigated in order to reduce these costs and optimize pesticide applications. One such method would be to detect the volatile organic compounds (VOCs) emitted from cotton plants damaged by stink bugs. A portable device was developed to draw VOCs from the head space of a cotton boll over carbon black-polymer composite sensors. From the response of these sensors, this device would indicate if the boll was fed upon by a stink bug or not. The device was $100 \%$ accurate in distinguishing bolls damaged by stink bugs from undamaged controls when tested under training conditions. However, the device was only $57.1 \%$ accurate in distinguishing damaged from undamaged bolls when tested $24 \mathrm{~h}$ after it was trained. These results indicated that this device was capable of classifying cotton as damaged or undamaged by differentiating VOCs released from undamaged or damaged bolls, but improvements in design are required to address sensitivity to fluctuations in environmental conditions.

\section{Introduction}

Cotton containing transgenes from the bacterium Bacillus thuringiensis $(B t)$ subspecies kurstaki Berliner has significantly reduced the amount of foliar-applied insecticides used to control major pests of the crop, such as tobacco budworm, Heliothis virescens (F.) and bollworm, Helicoverpa zea (Boddie) (Lepidoptera: Noctuidae). However, because phytophagous species of stink bugs are no longer being controlled coincidentally by applications of these insecticides, these insects have become major pests capable of causing significant economic damage to cotton [1-3]. Insecticide use for control of stink bugs increased from 0 to 4 million applications from 1995 to 2001, costing cotton producers \$27 million [4]. Losses due to stink bugs in 2011 were estimated to be over $\$ 48$ million in the USA, with control costs exceeding $\$ 5.3$ million [3].

In order to preserve the benefits of $B t$ cotton and minimize the amount of insecticides needed for acceptable control, detection methods are needed that provide enhanced measures of pest density or damage, with the ultimate goal of applying pesticides only to areas that harbor insects and exceed damage thresholds. A major constraint to pest control is the difficulty associated with obtaining necessary information to make treatment decisions. Current monitoring techniques for stink bugs in cotton include field sampling with a beat cloth to determine pest densities [5] and handpicking of bolls to assess pest damage [6]. Stink bugs have piercing-sucking mouthparts and feed on the developing seed inside of cotton bolls. This feeding leaves signs of 
injury inside bolls in the form of callus wart-like growths [7]. A boll with at least one of these warts is counted as "damaged" when determining threshold levels and making treatment decisions. These methods are perceived as variable and time-consuming, and control decisions can often be based on insufficient information. More efficient methods must be found to assess pest density and damage levels so supplemental sprays for lepidopterous pests are not replaced with excessive sprays for stink bugs.

Because current detection methods are far less than optimal, novel sensing technologies for detecting stink bugs should be evaluated. Such methods include exploiting volatiles released from cotton damaged by these insects. Cotton plants and bolls release chemicals as part of a defensive mechanism against pests [8], or as a by-product of chemical reactions in bolls damaged by sucking bugs [ 9 , 10]. These chemicals which include various homoterpenes and monoterpenes [11,12], are molecularly specific, normally volatile, and potentially detectible as a characteristic of stink bug presence and/or boll damage in cotton. Several chemicalspecific sensors are used to detect a broad range of alcohols, aldehydes, esters, hydrocarbons, and volatile sulfur compounds, as well as individual volatiles associated with fruit ripening across a wide concentration range [13, 14]. Several sensing technologies, such as metal oxide sensors, electrically conducting polymers, surface acoustic wave (SAW) sensors, and colorimetric sensors, are available for detecting volatile chemical. For example, Schutz et al. [15] used intact insect antennas as biosensors to detect volatile released by diseased potato tubers.

Because cotton releases volatiles systematically in response to piercing/sucking damage from hemipteran insects, these volatiles can potentially be detected as a characteristic of boll damage in cotton. Therefore, the detection of these volatiles can indirectly indicate the presence of these pests.

Carbon black-polymer composites have been shown to express variable resistance to electrical current in the presence of certain volatiles [16]. Each carbon black-polymer composite sensor responds specifically to an analyte, and an array of these sensors can be used to make a "fingerprint" of an analyte, which can be used to differentiate it from other analytes. The sensitivity of these sensors varies from $\mathrm{ppm}$ to $\mathrm{ppb}$, depending on the vapor pressure of the analyte [17]. Carbon black-polymer composites have been shown to have a distinct fingerprint when exposed to volatile organic compounds secreted by damaged plants [18]. That study investigated numerous compounds, including $\alpha$ pinene, limonene, and farnesene, compounds shown to be released by insect-damaged cotton [11]. The sensor which showed the greatest response to $\alpha$-pinene was poly(ethylene oxide), and the sensor which showed the greatest response to both limonene and farnesene was polyethylene [18].

Carbon black-polymer composite sensors have a number of benefits over similar sensors. These sensors have been shown to outperform tin oxide and conducting polymer arrays in resolving analytes [19]. In addition, these sensors respond linearly to relative humidity, do not degrade upon exposure to humidity, and can discriminate analytes in high humidity [17].

Cotton volatiles have previously been detected using a commercially available electronic nose $[12,20]$. These studies demonstrated that the hand-held Cyranose 320 (Smith Detection, Pasadena, CA; now supplied by Sensigent, Baldwin Park, CA, USA) could identify damaged bolls with 90\% accuracy and undamaged bolls with $80 \%$ accuracy in laboratory conditions [20] and up to $100 \%$ accuracy in field conditions [12]. The Cyranose 320 is equipped with sensors made from various types of carbon black-polymer composites; however, it is expensive $(>\$ 10,000)$, requires trained personnel for analysis, and lacks real-time software for "on-the-go" measurements of plant volatiles.

This research was aimed at developing a pest and damage (PAD) detector using carbon black-polymer composites to detect cotton bolls fed upon by insects. This device would be used specifically by growers and consultants for detecting bolls damaged by stink bugs, replacing the practice of counting insects and hand opening bolls. This device would also be less expensive, readily available, and easy to interpret and provide rapid results for in-field decision making. Furthermore, because optimal carbon black-polymer composites were identified for detecting damaged cotton, our specific array of sensors will not require training, be cheaper than commercial units ( $\$ 500$ versus $\$ 10 \mathrm{~K}$ ), and reduces total sampling time (10 s versus $60 \mathrm{~s}$ ) compared with a commercial version previously tested $[12,20]$.

\section{Methods}

2.1. Collection and Rearing of Insects. Adults of Nezara viridula were used for this experiment. Some insects were reared from eggs from mated females in the laboratory, and some were collected from cotton and soybean fields in late spring and early summer of 2012 at the Edisto Research and Education Center near Blackville, South Carolina. Stink bugs were reared and held in plastic cages and fed fresh green beans and raw peanuts [21]. The cages were held in a controlled environment at $30^{\circ} \mathrm{C}$ and $70 \%$ relative humidity with a photoperiod of $14: 10(\mathrm{~L}: \mathrm{D}) \mathrm{h}$.

\subsection{Rearing and Use of Plants. Cotton, Gossypium hirsutum} (L.), variety DP 164 B2RF (Delta and Pine Land 164 Bollgard 2 Roundup-Ready Flex), was planted at the Edisto Research and Education Center near Blackville, South Carolina. Plants were blooming and setting bolls during experimentation.

2.3. Fabrication of Sensors. Carbon black-polymer composite sensors were constructed by drop coating a carbon blackpolymer mixture onto a custom printed circuit board (PCB). The custom PCBs were fabricated by Pad2Pad (Mahwah, NJ, USA) and were $29 \mathrm{~mm} \times 14 \mathrm{~mm}$ with 4 sets of 6 interdigitated electrodes (Figure 1). The electrodes were 200 microns wide, spaced 500 microns from center to center. Composite solutions were made using $20 \mathrm{mg}$ of suspended carbon black (BP2000, Cabot Co., Billerica, MA, USA) and $80 \mathrm{mg}$ of polymer in $10 \mathrm{~mL}$ of solvent. Polymers used were poly(ethylene 


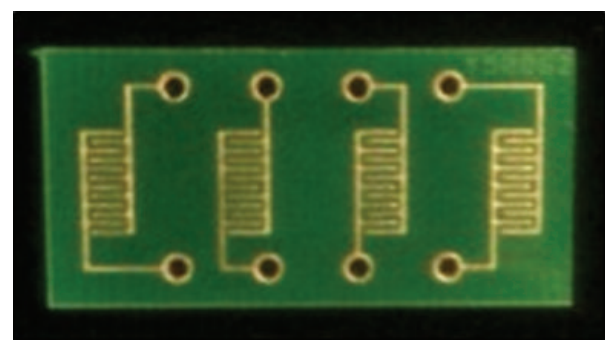

FIGURE 1: Printed circuit board for carbon black-polymer composite sensors.

TABLe 1: Polymers used to fabricate carbon black-polymer composite sensors. Baseline resistances were taken at $52.4 \% \mathrm{RH}$ and $36.1^{\circ} \mathrm{C}$.

\begin{tabular}{lcc}
\hline $\begin{array}{l}\text { Sensor } \\
\text { number }\end{array}$ & Polymer & Baseline resistance $[\mathrm{k} \Omega]$ \\
\hline 4 & Poly(styrene-co-allyl alcohol) & 170 \\
8 & Poly(vinylpyrrolidone) & 77 \\
9 & Poly(ethylene glycol) & 760 \\
10 & Poly(ethylene oxide) & 9.0 \\
\hline
\end{tabular}

glycol), poly(ethylene oxide), poly(styrene-co-allyl alcohol), and poly(vinylpyrrolidone) (Table 1). These polymers were chosen based on their use in previous research $[16,18]$. Tetrahydrofuran was used as the solvent for all sensors, except benzene was used for the poly(ethylene oxide) sensor. All polymers and solvents were ordered from Sigma-Aldrich (St. Louis, MO, USA). Solutions were sonicated for one min prior to drop coating to ensure carbon black suspension and then immediately drop coated and allowed to dry. This process was repeated until resistance was less than $1 \mathrm{M} \Omega$. Our initial testing with sensor location on the PCBs indicated that sensor order did not affect sensor response, so sensors 9, 10, 4, and 8 were randomly assigned to an array in positions $1,2,3$, and 4 , respectively, with position 1 being closest to the sample input.

2.4. Development of Device. Components of the PAD detector (Figure 2) were assembled into an ABS enclosure (Model 100-42-NO-E, Box Enclosures and Assembly Services, Lake Bluff, IL, USA). The microdiaphragm pump (Model NMS020L, KNF Neuberger Inc., Trenton, NJ, USA) was connected by $0.318 \mathrm{~cm}$ OD, $0.159 \mathrm{~cm}$ ID polyethylene tubing to a stainless steel sensor box as well as a subminiature solenoid valve (Model GH3115-C203, Gems Sensors \& Controls, Plainville, CT, USA). Approximately $58 \mathrm{~cm}$ of polyethylene tubing was used for sample collection, and $16 \mathrm{~cm}$ of tubing was used for ambient air collection in total. The headers of the sensor PCB were inserted through the stainless steel sensor box and inserted into a socket on the control circuit PCB. A $12 \mathrm{~V}, 4.5 \mathrm{Ah}$ lithium ion rechargeable battery (Model LBP-124500, MG Electronics, Hauppauge, NY, USA) was used as a power supply, and the Arduino Uno R3 was used as the microcontroller board (Arduino LCC, Italy). Also, new relative humidity and temperature sensors were added to record environmental variables. The temperature sensor used was model LM35CH (National Semiconductor, Santa Clara,

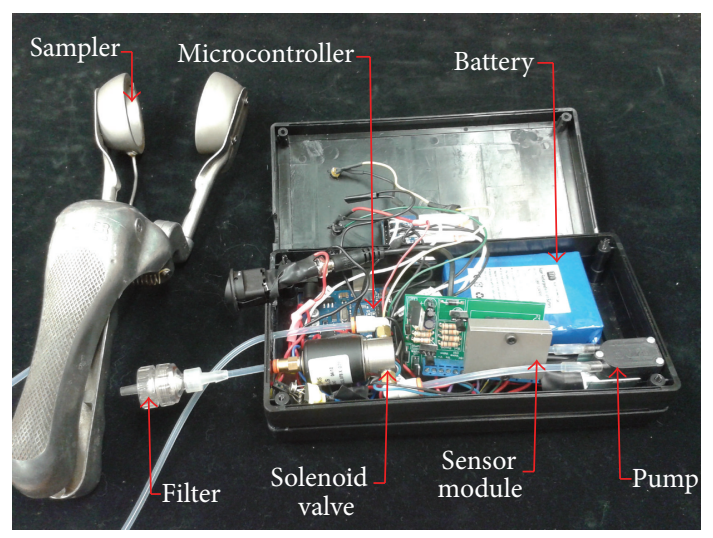

FIgURE 2: Components of the pest and damage detector.

CA, USA), and the humidity sensor used was HIH-4000-003 (Honeywell, Morristown, NJ, USA).

The control circuit (Figure 3) was printed to the control circuit PCB. The $12 \mathrm{~V}$ was supplied by the battery. The Arduino Uno $R 3$ was responsible for providing the digital output for controlling the pump and valve.

The sensor circuit (Figure 4) was also printed to the control circuit PCB. The Arduino Uno R3 supplied the $5 \mathrm{~V}$ and recorded the voltage drop across the carbon blackpolymer composite sensors $R_{1}$ to $R_{4}$.

In addition to the Arduino Uno R3, a portable datalogger (midi logger GL220, Graphtec Corporation, Yokohama, Japan) also input these voltage drops across the carbon blackpolymer composite sensors via an 8-pin DIN connector. The datalogger was used during the development phase in order to visualize the data in-field and also because it has a greater resolution than the Arduino Uno R3.

An activated charcoal filter (developed in-house) was added to the ambient air intake in order to reduce volatiles in the ambient air, and a sampler was added to the sample air intake in order to reduce volatile head space and reduce false negatives (Figure 2). The Arduino Uno was programmed to draw a stream of ambient air through the filter, valve, and pump and then across an array of four carbon blackpolymer composite sensors during the purge cycle. During the sampling cycle, a stream of VOCs from around a cotton boll was drawn from the sampler, through the filter, valve, and pump and then across an array of four carbon black-polymer composite sensors. The change in resistance of the sensors was calculated during the sampling cycle.

2.5. Field Testing of Device. Cages were placed over forty cotton bolls (each about 12-14 days after anthesis) by securing nylon stockings over polystyrene foam cups as described by Greene et al. [7] and Degenhardt et al. [12]. A stink bug was placed inside the cages on twenty of the bolls and allowed to feed for 48 to $72 \mathrm{~h}$. Twenty cotton bolls caged without bugs were used as controls. Cotton bolls were selected in pairs, with treatments applied to bolls of adjacent plants. Pairs of bolls were located 15 to $30 \mathrm{~m}$ apart in rows which were spaced approximately $1 \mathrm{~m}$ apart. After $48 \mathrm{~h}$ of feeding, field testing 


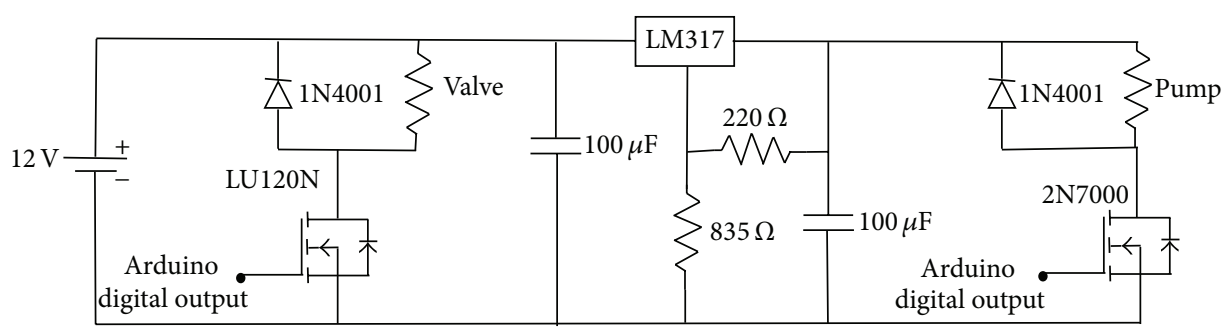

FIgURE 3: Control circuit for controlling the pump and valve with the Arduino microcontroller board.

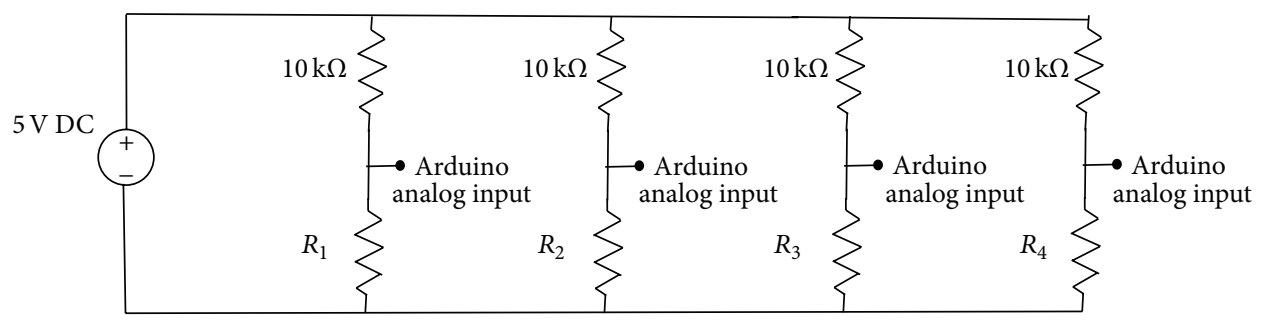

Figure 4: Sensor circuit for measuring voltage drop across the sensors using the Arduino microcontroller board. Resistors $R_{1}-R_{4}$ represent the carbon black-polymer composite sensors.

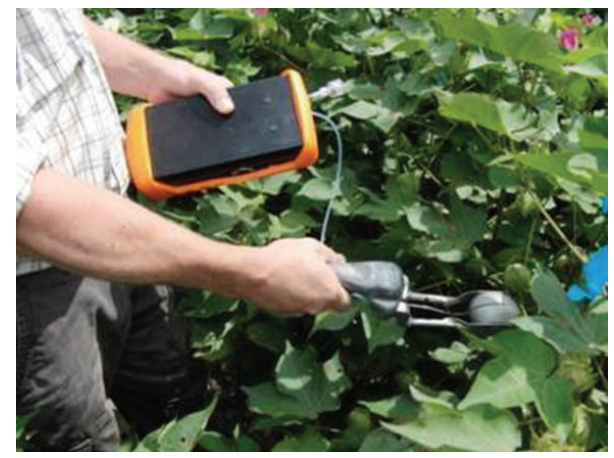

FIGURE 5: Field sampling cotton bolls with pest and damage (PAD) detector.

was performed on 2 August 2012 between 0944 and 1004 h, and, after $72 \mathrm{~h}$ of feeding, field testing was performed on 3 August 2012 between 0956 and 1048 h at the Edisto Research and Education Center in Blackville, South Carolina.

To sample cotton volatiles, the cages were removed, and the boll was placed in the boll sampler (Figure 5). Ambient air was pumped over the sensors to purge them for $5 \mathrm{~s}$, and then the solenoid valve was activated to pump air from the boll sampler over the sensors for $11 \mathrm{~s}$. A $5 \mathrm{~s}$, postsample purge cycle followed.

Seven analog input channels of the datalogger were used. The first four channels were used to record the voltage drop across the carbon black-polymer sensors. The fifth channel was used to monitor the status of the solenoid valve. The sixth and seventh channels were used for analog output from the temperature and humidity sensors, respectively. The voltage range for all channels was $\pm 5 \mathrm{~V}$, except a voltage range of $\pm 1 \mathrm{~V}$ was used for channel six. A sampling frequency of $10 \mathrm{~Hz}$ was used for all channels.

The resistances of the sensors were calculated using the voltage drop across the sensor. A calibration curve was created for each sensor position using known resistors and the following equation:

$$
R^{-1}=a V^{-1}+b
$$

where $R$ is the resistance of the resistor, $V$ is the measured voltage drop across the resistor, and $a$ and $b$ are constants. This calibration equation was used to account for the internal resistance of the microcontroller and datalogger in parallel with the sensors.

The percent change in resistance was calculated by dividing the difference between the maximum and baseline resistances by the baseline resistance. The baseline resistance was defined as the sensor resistance immediately after the solenoid valve was energized, and the maximum resistance was defined as the largest resistance measured during the sampling cycle. These changes in resistance were used as features for detection. Samples from bolls which had not produced internal signs of feeding injury (i.e., warts) after $72 \mathrm{~h}$ and samples from bolls where the stink bugs had died during testing were discarded.

For clarity, data were graphed as a 3-period central moving average. Each datum point was graphed as the average of that datum point, the datum point immediately preceding it, and the datum point immediately after it. This allowed the trend of data to be observed more easily.

After $48 \mathrm{~h}$, the mean change in resistance for each sensor was compared between treatments by Student's $t$-test. Equality of variances was verified by $F$-test, and normality was verified by histogram. A logistic regression was made using features from sensors which showed a significant difference 


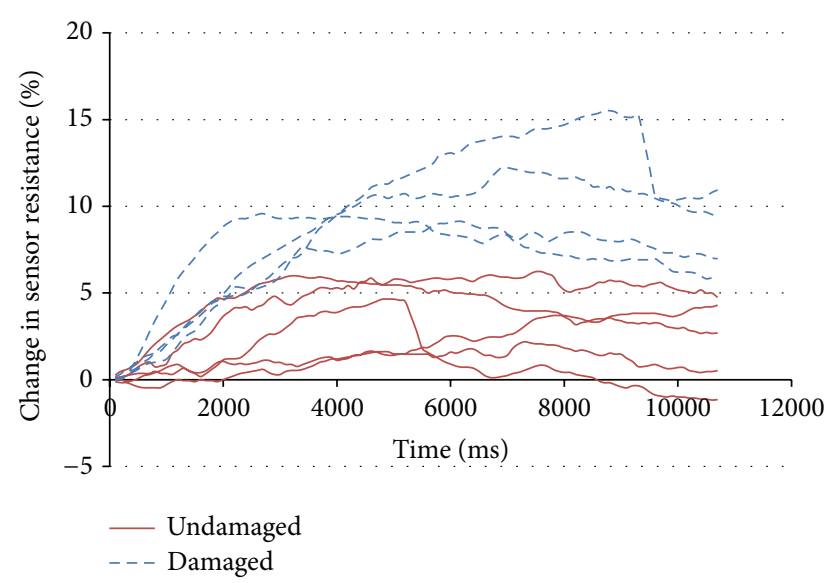

FigURE 6: Sensor response of sensor 8 to undamaged and damaged cotton bolls after $48 \mathrm{~h}$. Data are shown as a 3-period (300 ms) central moving average.

between treatments and verified using leave-one-out cross validation.

After 48 to $72 \mathrm{~h}$, significance of differences between changes in resistances between treatments was determined by paired $t$-test. Paired $t$-test was chosen to minimize effects from variables based on location and environmental factors such as temperature and humidity. Normality was verified by histogram. A significance level of 0.05 was used for all analyses.

\section{Results}

After $48 \mathrm{~h}$, there was a significant difference in percent change of resistance for undamaged and damaged bolls with sensor 8 $(t=3.14, \mathrm{df}=7$, and $P=0.0163)$ after a $3 \mathrm{~s}$ sample (Table 2$)$. Differences in sensor response of sensor 8 to undamaged and damaged bolls were notable after a few seconds of sampling (Figure 6). All samples taken after $48 \mathrm{~h}$ were taken between 54.3 and $62.3 \%$ relative humidity and between 32.3 and $37.3^{\circ} \mathrm{C}$.

A logistic regression using the resistance change for sensor 8 after $3 \mathrm{~s}$ of sampling was $77.7 \%$ accurate. However, a logistic regression using the resistance change for sensor 8 after $6 \mathrm{~s}$ of sampling was 100\% accurate in distinguishing the sensor response from undamaged and damaged bolls. This logistic regression was $57.1 \%$ accurate in classifying undamaged and damaged bolls after $72 \mathrm{~h}$.

After $72 \mathrm{~h}$, no sensors showed a significant difference between treatments with a $6 \mathrm{~s}$ sample, using a Student's $t$-test without accounting for temperature or humidity (Table 3 ). However, sensor 8 showed an exponential response with respect to temperature. The sensor response increased as the air temperature increased (Figure 7). Also, the sensor showed an exponential response with respect to relative humidity (Figure 8). The sensor response decreased as the relative humidity increased. Sensor 8 showed over a $10.0 \%$ change in resistance for undamaged bolls and over an $18.0 \%$ change in resistance for damaged bolls after $72 \mathrm{~h}$ within $6 \mathrm{~s}$ of sampling
TABLE 2: Mean $( \pm$ SD) maximum change in resistance for various carbon black-polymer composite sensors in response to volatiles from undamaged and damaged bolls after $48 \mathrm{~h}$ using a 3, 6, and 11 s sample. Asterisks $(*)$ indicate statistically significant differences between treatments (Student's $t$-test, unequal sample sizes, equal variance, 0.05 significance level).

\begin{tabular}{lccc}
\hline Sample & Sensor number & $\begin{array}{c}\text { Control [\%] } \\
n=5\end{array}$ & $\begin{array}{c}\text { Damaged [\%] } \\
n=4\end{array}$ \\
\hline \multirow{3}{*}{$3 \mathrm{~s}$} & 9 & $1.39 \pm 1.36$ & $0.349 \pm 0.698$ \\
& 10 & $0.542 \pm 0.262$ & $0.778 \pm 0.423$ \\
& 4 & $1.40 \pm 0.409$ & $1.50 \pm 0.184$ \\
& 8 & $3.13 \pm 2.29^{*}$ & $7.43 \pm 1.63^{*}$ \\
\hline \multirow{3}{*}{$\mathrm{s}$} & 9 & $1.76 \pm 1.11$ & $0.349 \pm 0.698$ \\
& 10 & $0.542 \pm 0.262$ & $0.845 \pm 0.445$ \\
& 4 & $1.45 \pm 0.373$ & $1.60 \pm 0.107$ \\
& 8 & $4.24 \pm 2.03^{*}$ & $10.9 \pm 1.98^{*}$ \\
\hline \multirow{4}{*}{$\mathrm{s}$} & 9 & $2.24 \pm 1.58$ & $0.795 \pm 0.932$ \\
& 10 & $0.542 \pm 0.262$ & $0.845 \pm 0.445$ \\
& 4 & $1.45 \pm .373$ & $1.60 \pm 0.107$ \\
& 8 & $4.76 \pm 1.63^{*}$ & $11.7 \pm 3.00^{*}$ \\
\hline
\end{tabular}

TABLE 3: Mean $( \pm S D)$ maximum change in resistance for various carbon black-polymer composite sensors in response to volatiles from undamaged and damaged bolls after $72 \mathrm{~h}$ using a $6 \mathrm{~s}$ sample.

\begin{tabular}{lcc}
\hline Sensor number & Control [\%] & Damaged [\%] \\
& $n=8$ & $n=8$ \\
\hline 9 & $2.17 \pm 2.12$ & $2.40 \pm 1.94$ \\
10 & $0.418 \pm 0.503$ & $0.270 \pm 0.497$ \\
4 & $1.05 \pm 0.300$ & $1.30 \pm 0.393$ \\
8 & $7.20 \pm 4.32$ & $9.14 \pm 7.08$ \\
\hline
\end{tabular}

TABLE 4: Mean $( \pm S D)$ differences in maximum change in resistance for various carbon black-polymer composite sensors in response to volatiles from undamaged and damaged bolls after $6 \mathrm{~s}$ sample. $N$ $=13$. Asterisks $(*)$ indicate differences between treatment means significantly differ from zero (paired sample $t$-test, 0.05 significance level).

\begin{tabular}{lc}
\hline Sensor number & Difference between treatments [\%] \\
\hline 9 & $0.20 \pm 2.3$ \\
10 & $-0.050 \pm 0.61$ \\
4 & $0.20 \pm 0.41$ \\
8 & $3.9 \pm 5.0^{*}$ \\
\hline
\end{tabular}

(Figure 9). Samples shown in Figure 9 were taken between 45.4 and $47.4 \%$ relative humidity and between 37.1 and $39.3^{\circ} \mathrm{C}$.

In order to account for the effects of environmental factors, data after both 48 and $72 \mathrm{~h}$ were examined by paired $t$-test. After 48 to $72 \mathrm{~h}$, sensor 8 showed a significant average difference between pairs $(t=2.8, \mathrm{df}=12$, and $P=0.016)$ after $6 \mathrm{~s}$ of sampling (Table 4 ). 


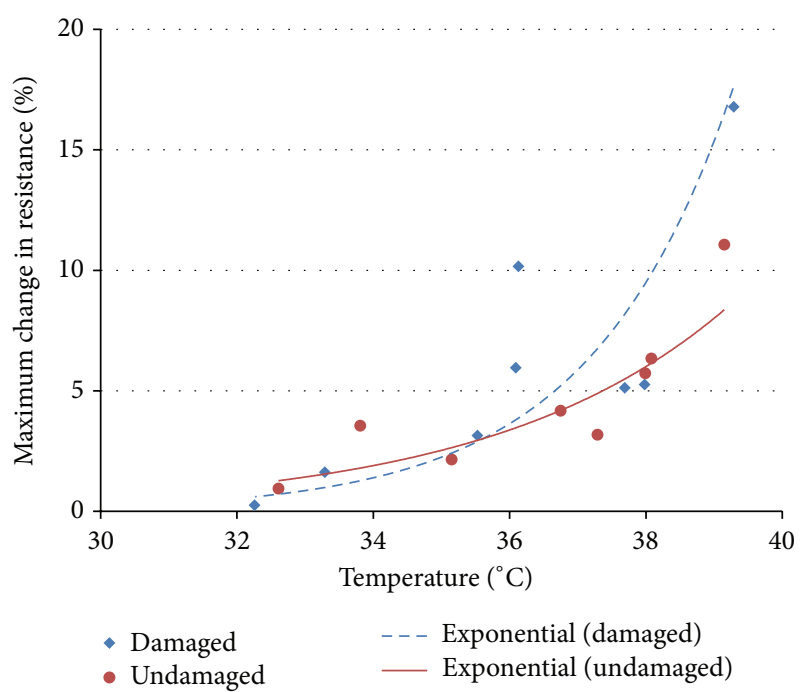

Figure 7: Maximum sensor response of sensor 8 at various temperatures to undamaged and damaged cotton bolls after $72 \mathrm{~h}$ with $6 \mathrm{~s}$ sample. Lines represent an exponential regression for responses to damaged and undamaged bolls.

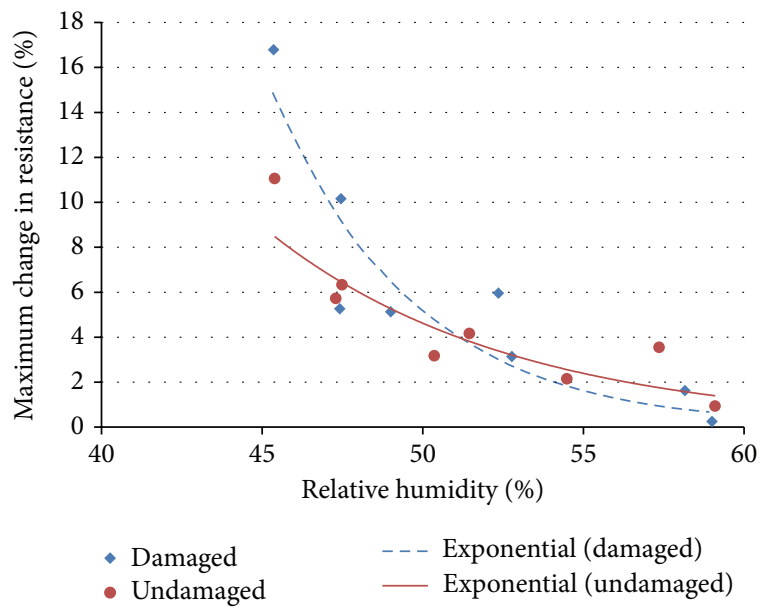

FIGURE 8: Maximum sensor response of sensor 8 at various relative humidity to undamaged and damaged cotton bolls after $72 \mathrm{~h}$ with $6 \mathrm{~s}$ sample. Lines represent an exponential regression for responses to damaged and undamaged bolls.

\section{Discussion}

Several studies have demonstrated the potential for using electronic nose technology to monitor pest damage in crop plants. Rice plants subjected to different densities of adult brown plant hopper, Nilaparvata lugens (Stål), were discriminated with $70 \%$ accuracy using stepwise discriminant analysis of electronic nose sensor data [22]. Electronic nose devices have also been used successfully to discriminate among VOC profiles released from cucumber, tomato, and green pepper plants subjected to pest and disease attack [23]. In this study, the prototype PAD detector showed similar capabilities in discriminating between damaged and healthy bolls compared

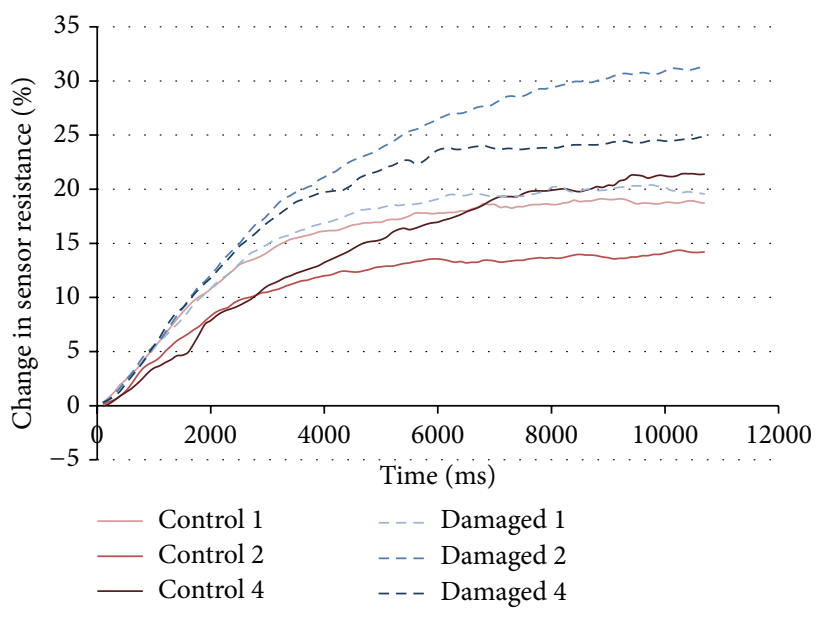

Figure 9: Response of sensor 8 to undamaged and damaged cotton bolls after $72 \mathrm{~h}$. Data are shown as a 3-period $(300 \mathrm{~ms})$ central moving average.

with field studies using a commercially available trained device [12].

Testing after $48 \mathrm{~h}$ showed that sensor 8 was able to differentiate damaged bolls from undamaged bolls. A logistic regression indicated that the sensor could distinguish between undamaged and damaged bolls with $100 \%$ accuracy, which showed potential for using this sensor to detect stink bug damage. In comparison, under laboratory conditions, a commercially available, 32-sensor device (Cyranose 320), distinguished between undamaged and damaged bolls with 90\% accuracy [20]. Lan et al. [24] reported that a trial-anderror training process for the Cyranose 320 is the key to build a high-confidence predictive model for detecting $N$. viridula.

Testing after $72 \mathrm{~h}$, the logistic regression showed $57.1 \%$ accuracy and that no sensors were able to detect damaged bolls from undamaged bolls. This was likely due to effects of environmental factors such as temperature or relative humidity. Because more samples were collected after $72 \mathrm{~h}$ and sampled over a longer period, samples were collected over a larger range of temperature and relative humidity. This wide range of testing conditions could have contributed to the insignificance of the differences between treatments because the maximum change in resistance for sensor 8 varied exponentially with temperature and relative humidity. This indicated that the device was likely very sensitive to environmental factors and should be trained under the same conditions as testing. Sensor drift due to variation in temperature and humidity may be controlled by periodic calibration with an internal standard based on cotton volatiles [25]. This capability is potentially available with our PAD unit via software correction.

One of the potential benefits of using an electronic nose device would be quick decision making. The sampling time can potentially be reduced to $6 \mathrm{~s}$ with our prototype, compared with a sample time exceeding $20 \mathrm{~s}$ for manual boll examination. Using a $5 \mathrm{~s}$ purge cycle, this means total time from initiation to a decision could be $11 \mathrm{~s}$. This would be 
a desirable and minimal time for evaluation of individual bolls using a nondestructive technique.

Drawbacks of this device include the necessity of training the device under the same environmental conditions as those used for testing the device. Because it has been shown that environmental factors may affect sensor response, it would be beneficial to train the device in the same environmental conditions to minimize the effects of these factors. Future studies should include data collection in a variety of environmental conditions in order to account for environmental factors such as temperature or humidity. Alternatively, these factors may be controlled by standardizing conditions within the unit.

\section{Conclusion}

This study demonstrated the potential of utilizing volatiles released from damaged cotton bolls to assess stink bug damage using an electronic nose device (Clemson PAD). The sensors developed for this study were highly effective in discriminating between undamaged and damaged bolls and could be incorporated into improved commercial detectors for use by pest management professionals.

\section{Conflict of Interests}

The authors declare that they have no conflict of interests regarding the publication of this paper.

\section{Acknowledgments}

The author would like to acknowledge Dr. Ya-ping Sun for the use of his lab and Dr. Monica Veca for her help fabricating the sensors. Thanks are due to technical contribution no. 6296 of the Clemson University Experiment Station. The author would also like to acknowledge the support of Cotton Incorporated and the South Carolina Cotton Board. This material is based upon work supported by NIFA/USDA, under Project no. SC-1700369.

\section{References}

[1] A. R. Panizzi, J. E. McPherson, D. G. James, M. Javahery, and R. M. McPherson, "Stink bugs (Pentatomidae)," in Heteroptera of Economic Importance, C. W. Schaefer and A. R. Panizzi, Eds., pp. 421-474, CRC Press, Boca Raton, Fla, USA, 2000.

[2] J. K. Greene, S. G. Turnipseed, M. J. Sullivan, and O. L. May, "Treatment thresholds for stink bugs (Hemiptera: Pentatomidae) in cotton," Journal of Economic Entomology, vol. 94, no. 2, pp. 403-409, 2001.

[3] M. R. Williams, "Cotton insect losses-2011," in Proceedings of the Beltwide Cotton Conference, S. Boyd, M. Huffman, and B. Robertson, Eds., pp. 1013-1057, National Cotton Council of America, Orlando, Fla, USA, January 2012.

[4] M. R. Williams, “ Cotton insect losses-2001," in Proceedings of the Beltwide Cotton Conferences, January 2002, Atlanta, GA, J. McRae and D. A. Richter, Eds., National Cotton Council of America, Memphis, Tenn, USA, 2002.
[5] J. K. Greene, G. A. Herzog, and P. M. Roberts, "Management decisions for stink bugs," in Proceedings, Beltwide Cotton Production Research Conferences, C. P. Dugger and D. A. Richter, Eds., pp. 913-917, National Cotton Council of America, Anaheim, Calif, USA, January 2001.

[6] J. K. Greene, G. A. Herzog, P. M. Roberts, W. D. Duffie, and G. Wilson, "Using a damage threshold to manage stink bugs in cotton," Georgia Cotton Research and Extension Reports. UGA/CPES Research-Extension Publication No. 4:240-245, 2000.

[7] J. K. Greene, S. G. Turnipseed, M. J. Sullivan, and G. A. Herzog, "Boll damage by southern green stink bug (Hemiptera: Pentatomidae) and tarnished plant bug (Hemiptera: Miridae) caged on transgenic Bacillus thuringiensis cotton," Journal of Economic Entomology, vol. 92, no. 4, pp. 941-944, 1999.

[8] P. W. Paré and J. H. Tumlinson, "Plant volatiles as a defense against insect herbivores," Plant Physiology, vol. 121, no. 2, pp. 325-331, 1999.

[9] B. M. Drees and J. Jackman, Southern Green Stink Bug. Field Guide to Texas Insects, 1999, http://texasinsects.tamu.edu/ aimg73.html.

[10] L. Williams III and N. P. Tugwell, "Histological description of tarnished plant bug (Heteroptera: Miridae) feeding on small cotton floral buds," Journal of Entomological Science, vol. 35, no. 2, pp. 187-195, 2000.

[11] C. Rodriguez-Saona, S. J. Crafts-Brandner, L. Williams III, and P. W. Paré, "Lygus hesperus feeding and salivary gland extracts induce volatile emissions in plants," Journal of Chemical Ecology, vol. 28, no. 9, pp. 1733-1747, 2002.

[12] D. C. Degenhardt, J. K. Greene, and A. Khalilian, “Temporal dynamics and electronic nose detection of stink bug-induced volatile emissions from cotton bolls," Psyche, vol. 2012, Article ID 236762, 9 pages, 2012.

[13] J. Brezmes, E. Llobet, X. Vilanova, G. Saiz, and X. Correig, "Fruit ripeness monitoring using an Electronic Nose," Sensors and Actuators, B: Chemical, vol. 69, pp. 223-229, 2000.

[14] H. N. Norton, Biomedical Sensors: Fundamentals and Applications, Noyes Publications, Park Ridge, NJ, USA, 1982.

[15] S. Schutz, B. Weissbecker, U. T. Koch, and H. E. Hummel, "Detection of volatiles released by diseased potato tubers using a biosensor on the basis of intact insect antennae," Biosensors and Bioelectronics, vol. 14, no. 2, pp. 221-228, 1999.

[16] M. C. Lonergan, E. J. Severin, B. J. Doleman, S. A. Beaber, R. H. Grubbs, and N. S. Lewis, "Array-based vapor sensing using chemically sensitive, carbon black-Polymer resistors," Chemistry of Materials, vol. 8, no. 9, pp. 2298-2312, 1996.

[17] B. C. Muñoz, G. Steinthal, and S. Sunshine, "Conductive polymer-carbon black composites-based sensor arrays for use in an electronic nose," Sensor Review, vol. 19, no. 4, pp. 300-305, 1999.

[18] K. A. Weerakoon and B. A. Chin, "Detecting insect infestation using a carbon/polymer composite based sensor array," ECS Transactions, vol. 33, pp. 85-89, 2010.

[19] B. J. Doleman, M. C. Lonergan, E. J. Severin, T. P. Vaid, and N. S. Lewis, "Quantitative study of the resolving power of arrays of carbon black-polymer composites in various vapor-sensing tasks," Analytical Chemistry, vol. 70, no. 19, pp. 4177-4190, 1998.

[20] W. G. Henderson, A. Khalilian, Y. J. Han, J. K. Greene, and D. C. Degenhardt, "Detecting stink bugs/damage in cotton utilizing a portable electronic nose," Computers and Electronics in Agriculture, vol. 70, no. 1, pp. 157-162, 2010. 
[21] V. E. Harris and J. W. Todd, "Rearing the southern green stink bug, Nezara viridula, with relevant aspects of its biology," Journal of the Georgia Entomological Society, vol. 16, pp. 203-210, 1981.

[22] B. Zhou and J. Wang, "Use of electronic nose technology for identifying rice infestation by Nilaparvata lugens," Sensors and Actuators, B: Chemical, vol. 160, no. 1, pp. 15-21, 2011.

[23] J. Laothawornkitkul, J. P. Moore, J. E. Taylor et al., "Discrimination of plant volatile signatures by an electronic nose: a potential technology for plant pest and disease monitoring," Environmental Science \& Technology, vol. 42, no. 22, pp. 84338439, 2008.

[24] Y.-B. Lan, X.-Z. Zheng, J. K. Westbrook, J. Lopez, R. Lacey, and W. C. Hoffmann, "Identification of stink bugs using an electronic nose," Journal of Bionic Engineering, vol. 5, pp. 172$180,2008$.

[25] M. M. Macias, J. E. Agudo, A. G. Manso, C. J. G. Orellana, H. M. G. Velasco, and G. Caballero, "Improving short term instability for quantitative analyses with portable electronic noses," Sensors, vol. 14, no. 6, pp. 10514-10526, 2014. 

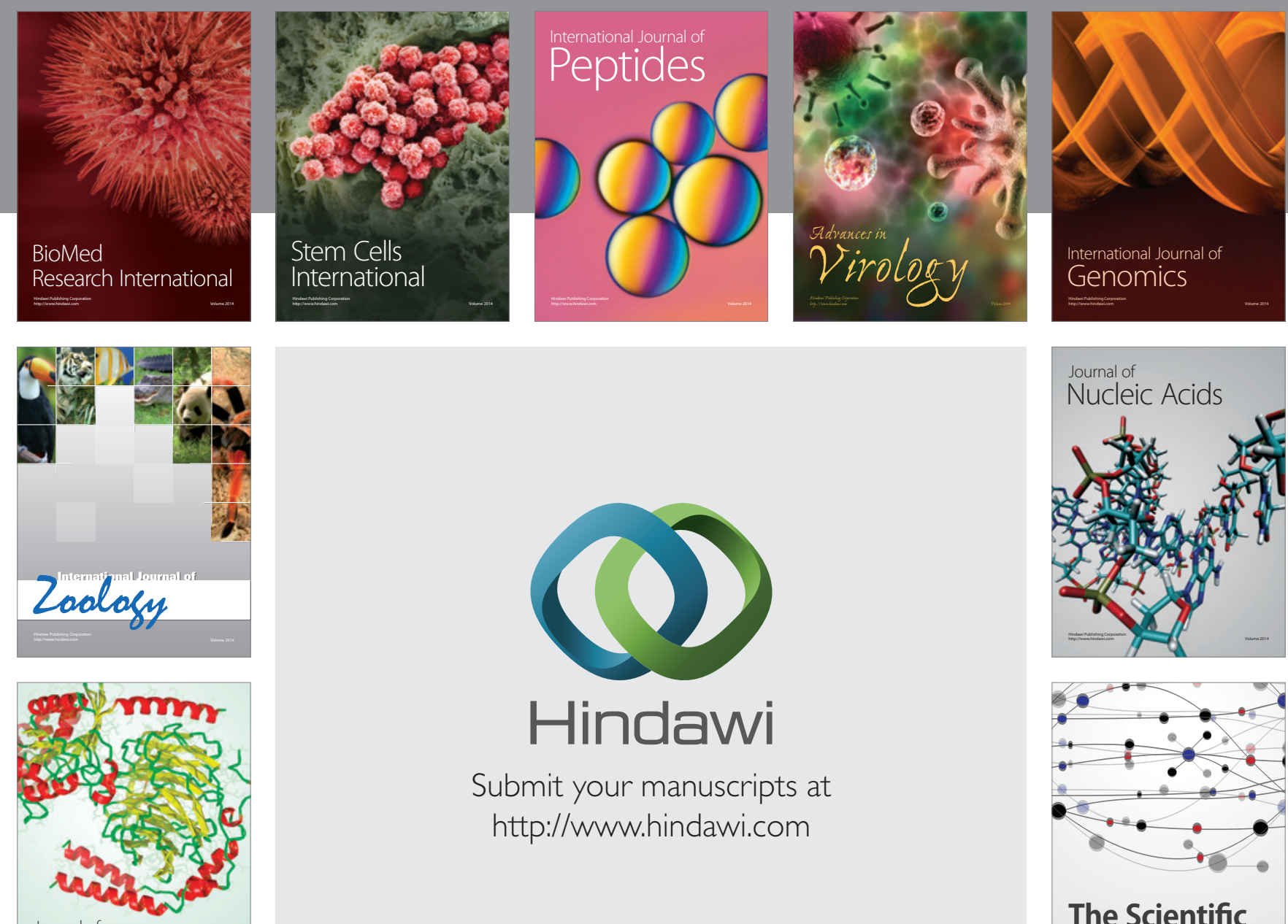

Submit your manuscripts at

http://www.hindawi.com

Journal of
Signal Transduction
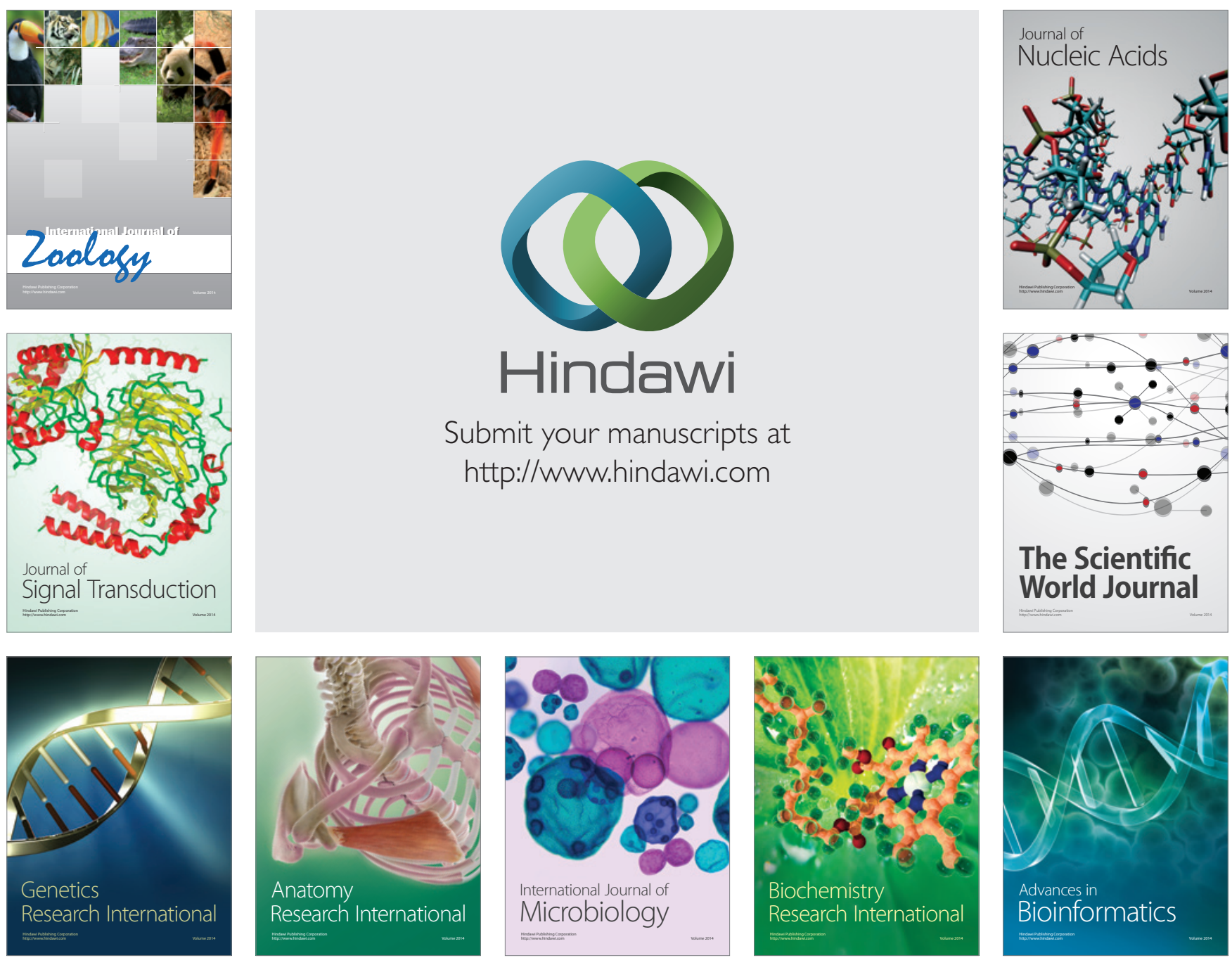

The Scientific World Journal
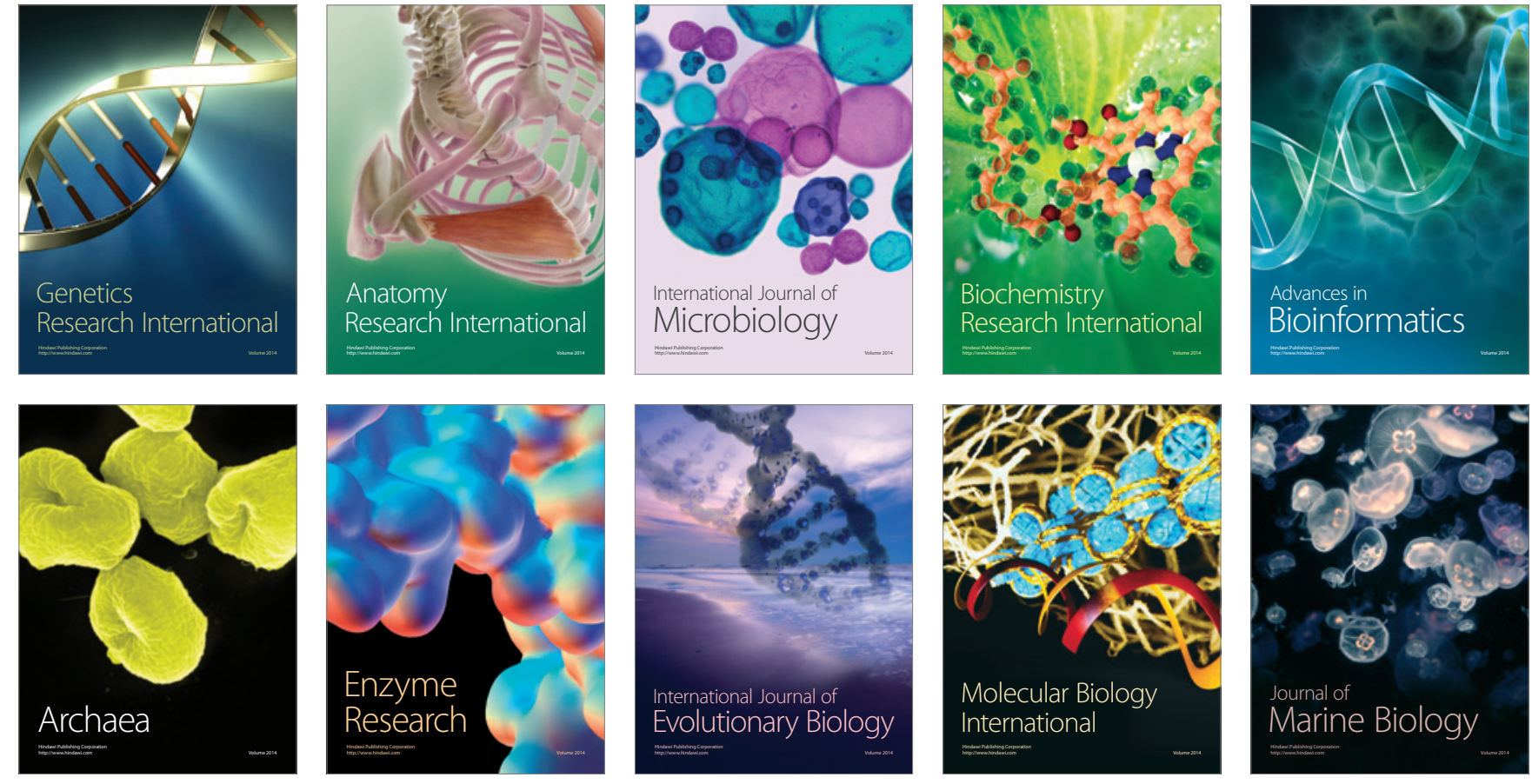